\title{
Photochromic Properties of Benzodixanthene Analogues Having Alkyl Group and Their Langmuir - Blodgett Films
}

\author{
Tomohiro WATANABE,,$^{\text {a) }}$ Chizuko YANASHIMA, ${ }^{\text {a) }}$ Takeshi KAWASHIMA, \\ Hiroo NAKAHARA, ${ }^{\text {b) }}$ and Sumio TOKITA ${ }^{\text {a) }}$ \\ a) Department of Applied Chemistry, Faculty of Engineering, Saitama University, \\ 255 Shimo-Ohkubo, Urawa, Saitama, 338-8570 Japan \\ b) Department of Chemistry, Faculty of Science, Saitama University, \\ 255 Shimo-Ohkubo, Urawa, Saitama, 338-8570 Japan
}

Benzo[1, 2, 3-kl: 4, 5, 6-k' $\left.l^{\prime}\right]$ dixanthene having amino, methyl, and nitro group was synthesized from 1,5-dichloroanthraquinone in four steps. After quaternization with iodoalkane, photochromic properties of monolayers on water surface and LB films on quartz glass were investigated.

Keywords: benzodixanthene, quaternization, photochromism, Langmuir Blodgett film

\section{Introduction}

Benzo[1, 2, 3-kl: 4, 5, 6-k'l']dixanthene (1a) and its analogues are well known as typical polycondensed aromatic compounds having photochromic properties.[1] Molecular design of analogues of $\mathbf{1 a}$ and their isomers were performed to predict absorption maxima of these compounds.[2] The conformations of their endoperoxides were investigated by semiempirical molecular orbital calculation and $\mathrm{X}$ ray crystallographic analysis.[3] Monolayers of benzodixanthene analogues with 2-pyridyl group on water surface were preliminarily examined.[4]

The Langmuir - Blodgett films of benzodixanthene analogues with alkyl chain, however,

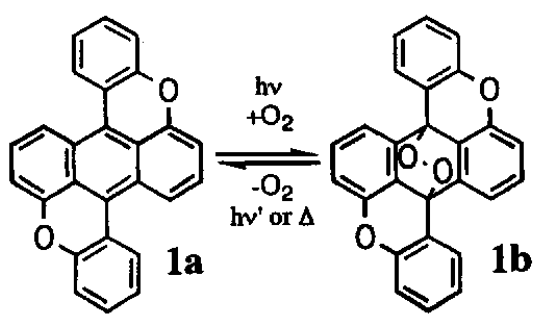

have not been reported. Here we present the properties of the monolayers and Langmuir Blodgett films of benzodixanthene analogue having with pyridyl group or amino group.

\section{Method}

Solvents and reagents were purified using literature method. Thin-layer chromatography (TLC) was performed on plastic or glass plate $(10 \times 5 \mathrm{~cm})$ coated with Merck 5735 silica gel $60 \mathrm{~F}$. Column chromatography was performed using Wakogel C-300 (200-300 mesh, Wako Pure Chemical Industries, Ltd.). Melting points were determined with a Büch melting point apparatus and were uncorrected. UV-VIS spectra were recorded on a Shimadzu UV-2100 spectrophotometer. IR spectra were obtained on Perkin-Elmer 1600 FT-IR. ${ }^{1}$ H-NMR spectra were recorded on Bruker AM-400 spectrometer, using tetramethylsilane as an internal standard. Synthetic routes to compounds $\mathbf{2}-\mathbf{5}$ are shown in Scheme 1. Molecular structures were optimized with AM1 procedure [5] and excitation energies were calculated by INDO/S.[6] Monolayers were spread from the benzene 
Scheme 1

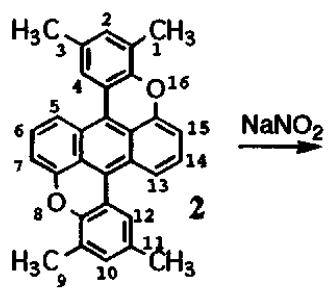

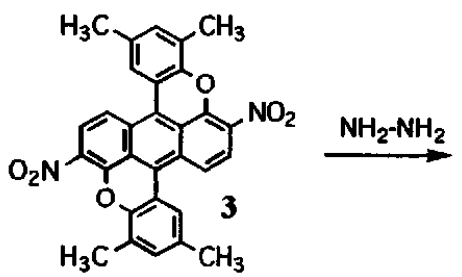

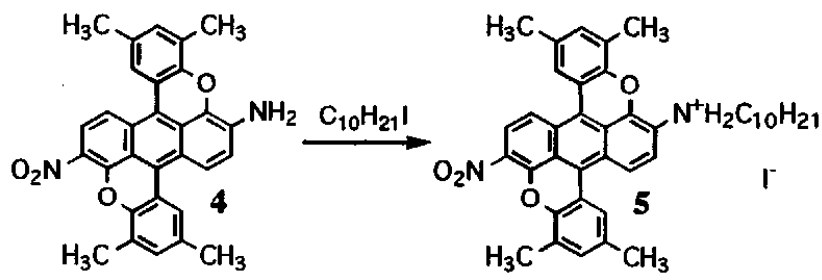

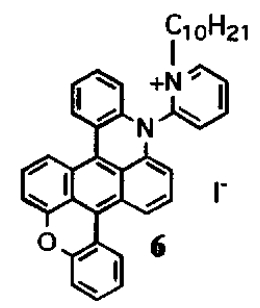

solution on the distilled water surface and the surface pressure - area $(\pi$ A) isotherms were measured by using a Lauda film balance. Y-type structures of built-up films on quartz plates were performed by vertical dipping method.

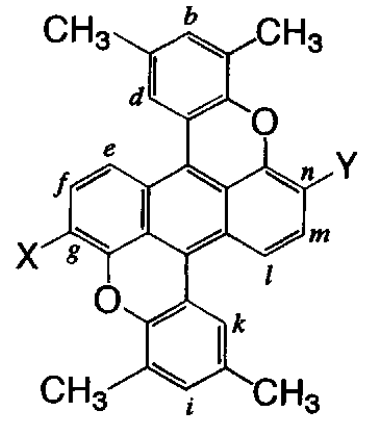

\section{Results and Discussion}

\subsection{Synthesis}

Nitration of 1 a under mild conditions yielded a mixture of mono-, di-, tri-, and higher nitro compounds. Tetramethyl derivative of $1 \mathrm{a}$ (namely, 2) gave similar mixture from which dinitro compound 3 could be isolated. The structure of 3 was determined by ${ }^{1}$ H-NMR (Table 1). The orientation of nitro group in this nitra-tion may be directed to 5-, 7-, 13-, and 15positions, however, 5- and 13-positions are unfavorable because of greater steric hindrance than 7- and 15-positions. Reduction of 3 gave monoamino derivative 4 in small yield. Quaternization of 4 gave 5 in $25 \%$ yield.

\subsection{Absorption maxima of UV-VIS spectra}

The absorption maxima of 3 and 4 shifted to longer wavelengths than that of 2 . On the other hand, the absorption maxima of 5 and 6 shifted to shorter wavelengths than those of 3 and 4 . These tendencies indicate that the electron withdrawing effect of the cation is much stronger than that of nitro group.[7] Correla-tion of the observed longest absorption maxima and the calculated values by INDO/S molecular orbital method is shown in Fig. 1.[8]

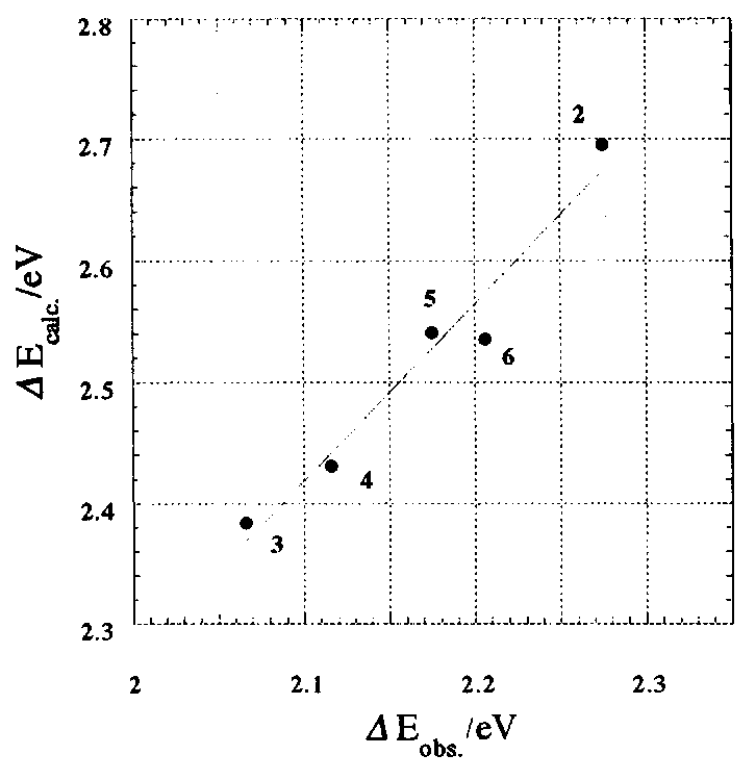

Fig. 1. $\Delta \mathrm{E}_{\text {obs. }}$ vs. $\Delta \mathrm{E}_{\text {calc. }}$ correlation of compounds 2 - 6 . 
Table 2 Photochromic properties of 2 - 5 to yield coresponding endoperoxides $1 \mathrm{~b}$.

\begin{tabular}{cccc}
\hline Compd. & $\mathrm{X}$ & $\mathrm{Y}$ & Relative rate \\
\hline 2 & $\mathrm{H}$ & $\mathrm{H}$ & 100 \\
3 & $\mathrm{NO}_{2}$ & $\mathrm{NO}_{2}$ & 2.7 \\
4 & $\mathrm{NO}_{2}$ & $\mathrm{NH}_{2}$ & 0.0033 \\
5 & $\mathrm{NO}_{2}$ & $\stackrel{+}{\mathrm{N}} \mathrm{H}_{2} \mathrm{C}_{10} \mathrm{H}_{21}$ & 0.8 \\
\hline
\end{tabular}

A ${ }^{1}$ H NMR analysis of benzodixanthene analogues gave a similar explanation to the above discussion concerning the electron withdrawing effects of nitro group and the cation in the compounds, $2-5$. The chemical shifts of $\mathrm{H}_{e}$, $\mathrm{H}_{l}, \mathrm{H}_{d}$, and $\mathrm{H}_{k}$ in 4 are observed at the lower field than those of typical aromatic protons depending on the steric hindrance.

\subsection{Photochromic properties}

Photochromic properties are measured with the same method reported previously. [9] Results are shown in Table 2.

3.4 Monolayers on water surface and LB films on quartz plates

The $\pi-A$ isotherms at various temperatures for the monolayers of each compound under the dark condition are shown in Fig. 2. The compound 6 with 2-pyridyl group and alkyl chain forms the most condensed monolayer with a limiting area of $30 \AA^{2} /$ molecule at $10{ }^{\circ} \mathrm{C}$, and 21 $\AA^{2} /$ molecule at $20^{\circ} \mathrm{C}$. On the other hand, the compound 5 with amino group and alkyl chain takes a limiting area of $49 \AA^{2} /$ molecule at $11^{\circ} \mathrm{C}$, and $45 \AA^{2}$ /molecule at $20^{\circ} \mathrm{C}$. The compound 5 forms rather expanded monolayers than the compound 6. In these cases, it is considered that $\pi$-conjugated systems of the molecular frameworks of 6 stand side by side on water surface, whereas the systems of 5 are not brought closely enough together. This fact seems to be ascribed the molecular structure, the direction of alkyl chain to the mother structure of polycondensed aromatic ring. The angles between the alkyl chain and the mother structure

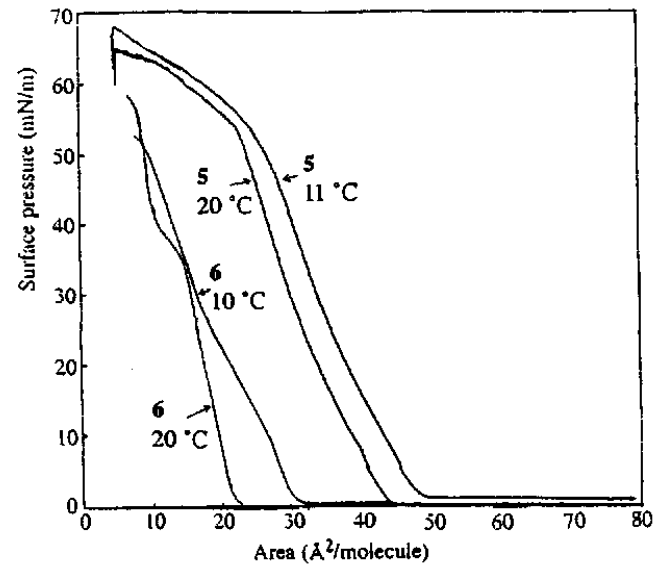

Fig. 2 Surface pressure - area isotherms of 5 and 6 under dark condition.

of 5 and 6 which are optimized by AM1 method are $146^{\circ}$ and $88^{\circ}$, respectively.

The angle between the alkyl chain and the mother structure of 6 is nearly perpendicular, so the condensed forces act between the alkyl chains. Therefore, the molecular orientation and packing indicate that the $\pi$-electron systems between the mother structures are overlapped and the limiting area is decreased. On the other hand, the angle of 5 is slanting, therefore it is hard to be overlapped between $\pi$-electron systems, and the limiting area is larger.

Spectral changes accompanied with the photochromic reactions of $5 a<-->5 b$ and $6 a<--$ $>6 \mathrm{~b}$ on quartz plates under irradiation of light ( $500 \mathrm{~W}$ Xe lamp at a distance of $40 \mathrm{~cm}$ ) above $500 \mathrm{~nm}$ or dark and thermal condition, are shown in Fig. 3.

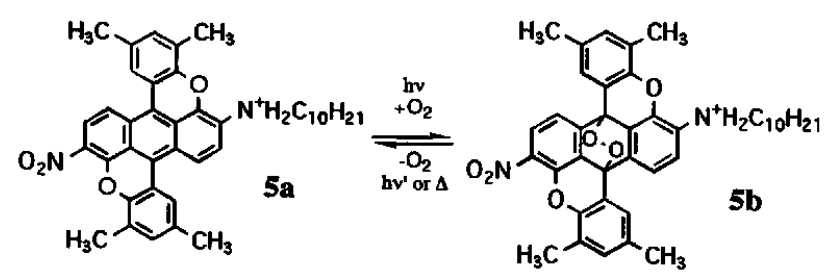

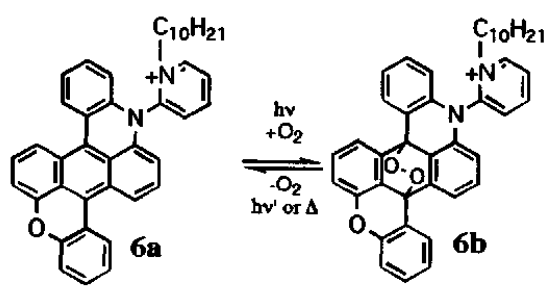



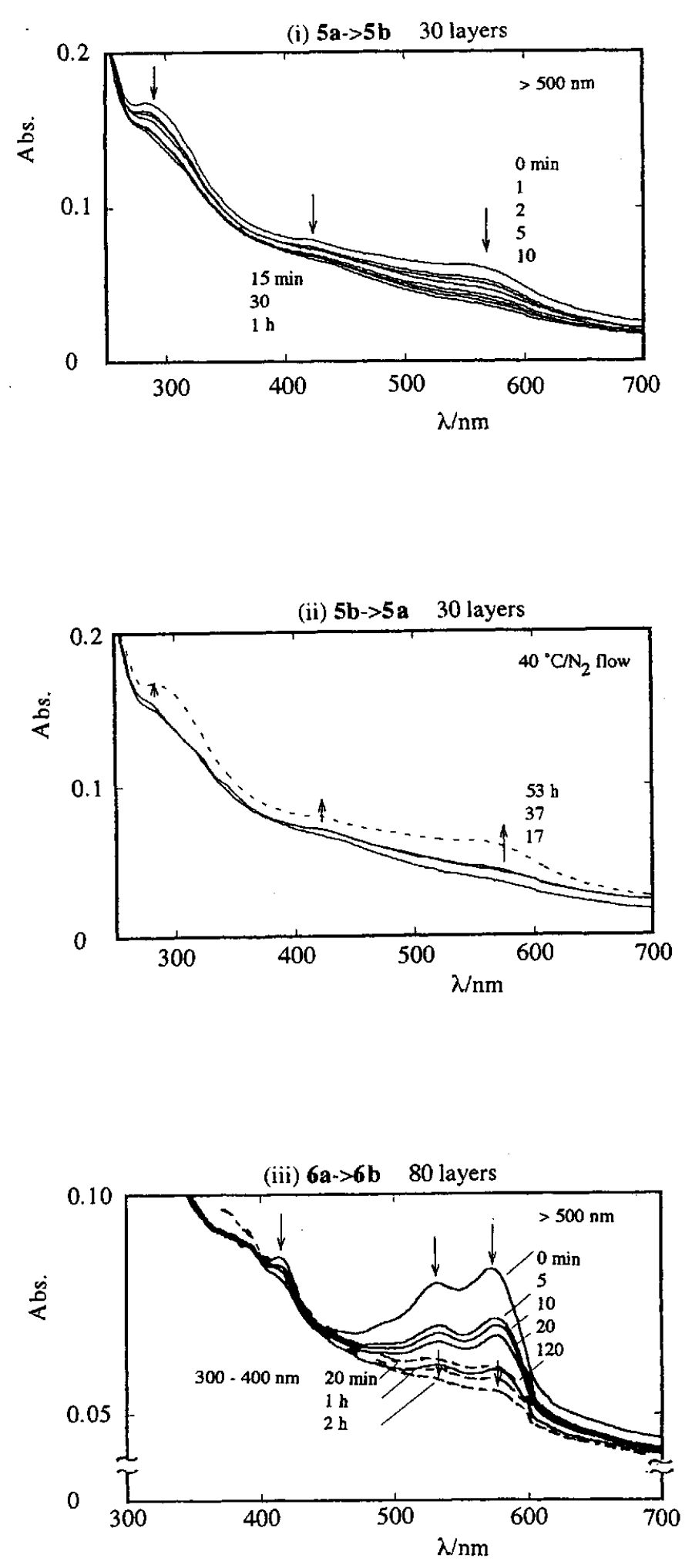

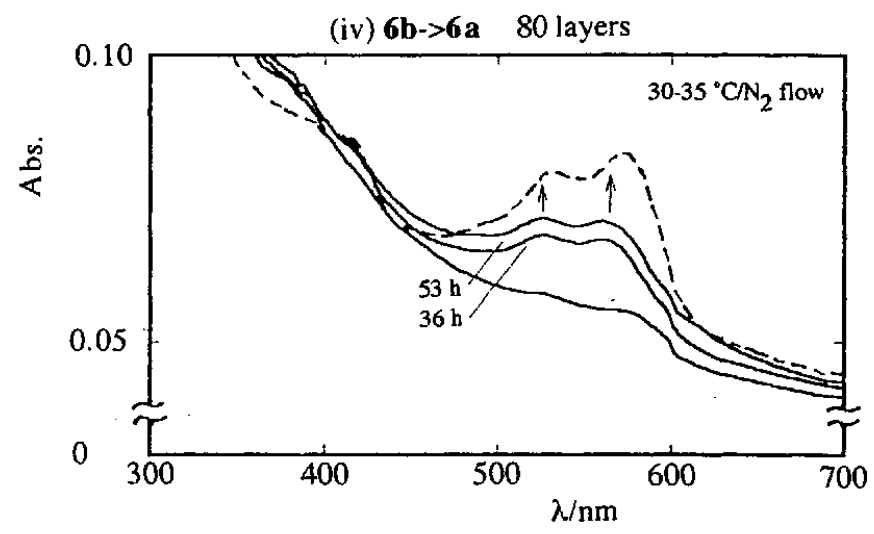

Fig. 3 UV-Vis spectral changes of 5 and 6 built up on quartz plates accompanied with

(i) and (iii) the $5 a->5 b$ and the $6 a->6 b$ reactions under photoirradiation and

(ii) and (iv) the $5 b->5 a$ and the $6 b->6 a$ reactions under dark and thermal condition, respectively.

\section{Synthesis}

1, 5-bis (2, 4-dimethylphenoxy)anthraquinone. A mixture of potassium 2, 4-dimethylphenoxide (2.4g, $15 \mathrm{mmol}), 1$, 5-dichloroanthraquinone (1.75 g, $6.5 \mathrm{mmol})$ [10], copper powder $(1.0 \mathrm{~g}, 16 \mathrm{mmol})$ and DMF $(20 \mathrm{ml})$ was heated under reflux at $150{ }^{\circ} \mathrm{C}$ for $3 \mathrm{~h}$. Sodium hydroxide $(0.1 \%, 50 \mathrm{ml})$ was added into the solution under heating. After filtration, the residue was washed with distilled water and dried. The product was recrystallized from xylene ( 40 ml). Yield $3.9 \mathrm{~g}$,, yellow needles, mp 242-243 ${ }^{\circ} \mathrm{C} ;{ }^{1} \mathrm{H}$ NMR $\left(\mathrm{CDCl}_{3} / \mathrm{TMS}, \delta \mathrm{ppm}\right) 6.87(\mathrm{~d}, \mathrm{~J}=$ $8.1 \mathrm{~Hz}, \mathrm{c}), 6.98(\mathrm{~d}, \mathrm{~J}=8.0 \mathrm{~Hz} \mathrm{~d}), 7.00(\mathrm{~d}, \mathrm{~J}=8.0$ $\mathrm{Hz}, \mathrm{b}), 7.06(\mathrm{~s}, \mathrm{a}), 7.57(\mathrm{t}, \mathrm{J}=8.0 \mathrm{~Hz}, \mathrm{e})$, and $7.99(\mathrm{~d}, \mathrm{~J}=8.0 \mathrm{~Hz}, \mathrm{f}$ ); UV-VIS ( $\mathrm{nm}$ in toluene) 373.

$1,3,9,11$-tetramethylbenzo $[1,2,3-k l: 4,5$, 6-k' $l^{\prime}$ ]dixanthene (2). A mixture of 1, 5-bis(2, 4-dimethylphenoxy)anthraquinone $(1 \mathrm{~g}, 2.2$ mmol), hydroquinone $(1.5 \mathrm{~g}, 13.6 \mathrm{mmol})$, anhydrous aluminum chloride $(13.1 \mathrm{~g}, 98.2 \mathrm{mmol})$ and sodium chloride $(2.6 \mathrm{~g}, 44.5 \mathrm{mmol})$ was heated at $180{ }^{\circ} \mathrm{C}$ for $10 \mathrm{~min}$, and stirring was continued at $145^{\circ} \mathrm{C}$ for $15 \mathrm{~min}$. After cooling, dilute hydrochloric acid $(2 \mathrm{~mol} / l, 50 \mathrm{ml})$ was added while stirring. Purification by usual 
method [4] gave $0.381 \mathrm{~g}$ of red needles. $\mathrm{mp}$ $229-230{ }^{\circ} \mathrm{C} ;{ }^{1} \mathrm{H} \mathrm{NMR}\left(\mathrm{CDCl}_{3} / \mathrm{TMS}, \delta \mathrm{ppm}\right)$ $6.91\left(\mathrm{~d}, \mathrm{~J}=7.4 \mathrm{~Hz}, \mathrm{H}_{\mathrm{g}}\right), 6.98\left(\mathrm{~s}, \mathrm{H}_{\mathrm{b}}\right), 7.30(\mathrm{t}, \mathrm{J}=$ $\left.8.6 \mathrm{~Hz}, \mathrm{H}_{\mathrm{f}}\right), 7.81\left(\mathrm{~s}, \mathrm{H}_{\mathrm{d}}\right)$, and $8.07(\mathrm{~d}, \mathrm{~J}=8.0 \mathrm{~Hz}$, $\mathrm{H}_{\mathrm{e}}$ ); UV-VIS ( $\mathrm{nm}$ in toluene $\left.(\log \varepsilon)\right) 545(4.27)$, 509 (4.21), and 413 (3.80).

7, 15-dinitro-1, 3, 9, 11-tetramethylbenzo[1, 2, 3-kl : 4, 5, 6- $\left.k^{\prime} l^{\prime}\right]$ dixanthene (3). Compound $2(0.4 \mathrm{~g}, 0.96 \mathrm{mmol})$, sodium nitrite $(772$ $\mathrm{mg}, 11.6 \mathrm{mmol})$, ammonium persulfate $(778 \mathrm{mg}$, $3.48 \mathrm{mmol})$ were stirred in acetnitril $(80 \mathrm{ml})$ at room temperature for $72 \mathrm{~h}$. Purification by silica gel column chromatography gave $0.310 \mathrm{~g}$ $(0.614 \mathrm{mmol}, 63.7 \%)$ of dark purple needles. mp $316^{\circ} \mathrm{C}$; IR( $\left.\mathrm{KBr} / \mathrm{cm}^{-1}\right)$ 1325( $\left.\mathrm{NO}_{2}\right)$; MS (EI) $(\mathrm{m} / \mathrm{z}) 504$ (MW 504.5); ${ }^{1} \mathrm{H}$ NMR ( $\mathrm{CDCl}_{3} / \mathrm{TMS}, \delta$ ppm) $7.07\left(\mathrm{~s}, \mathrm{H}_{\mathrm{b}}, \mathrm{H}_{\mathrm{j}}\right), 7.10\left(\mathrm{~s}, \mathrm{H}_{\mathrm{d}}, \mathrm{H}_{\mathrm{k}}\right), 7.21(\mathrm{~d}$, $\left.\mathrm{J}=8.5 \mathrm{~Hz}, \mathrm{H}_{\mathrm{f}}, \mathrm{H}_{\mathrm{m}}\right)$, and $8.38\left(\mathrm{~d}, \mathrm{~J}=8.5 \mathrm{~Hz}, \mathrm{H}_{\mathrm{e}}\right.$, $\mathrm{H}_{1}$ ); UV-VIS ( $\mathrm{nm}$ in toluene (loge)) $600(3.75)$, 556 (3.67), and 476 (3.94).

7-amino-1, 3, 9, 11-tetramethyl-15nitrobenzo[1, $\left.2,3-k^{\prime} l^{\prime}: 4,5,6-k^{\prime} l^{\prime}\right]$ dixanthene (4). Compound $3(400 \mathrm{mg}, 0.793 \mathrm{mmol})$ was stirred with active charcoal $(97.7 \mathrm{mg}$ ), iron (III) chloride (36 mg, $0.222 \mathrm{mmol}$ ) in ethanol $(100 \mathrm{ml})$ at $80{ }^{\circ} \mathrm{C}$ for $10 \mathrm{~min}$. A solution of hydrazine monohydrate $(80 \%, 0.452 \mathrm{~g}, 9.00$ mmol) in ethanol $(24 \mathrm{ml})$ was added, and stirred at $60{ }^{\circ} \mathrm{C}$ for $60 \mathrm{~h}$. The active charcoal was filtered off during hot. The filtrate was evaporated under reduced pressure. The residue was dissolved in chloroform and purified by column chromatography (chloroform/ silica gel) to give $86.2 \mathrm{mg}(0.182 \mathrm{mmol}, 23.0 \%)$ of black blue powder, mp $118^{\circ} \mathrm{C} ;{ }^{1} \mathrm{H}$ NMR (CDCl $3 / \mathrm{TMS}, \delta$ ppm) 4.15 (br, $\left.-\mathrm{NH}_{2}\right), 6.86\left(\mathrm{~s}, \mathrm{H}_{\mathrm{b}}\right), 6.94\left(\mathrm{~s}, \mathrm{H}_{\mathrm{j}}\right)$, $7.08\left(\mathrm{~s}, \mathrm{H}_{\mathrm{d}}\right), 7.16\left(\mathrm{~d}, \mathrm{~J}=9.1 \mathrm{~Hz}, \mathrm{H}_{\mathrm{f}}\right), 7.61(\mathrm{~d}, \mathrm{~J}=$ $\left.8.5 \mathrm{~Hz}, \mathrm{H}_{\mathrm{m}}\right), 7.91\left(\mathrm{~s}, \mathrm{H}_{\mathrm{k}}\right), 8.10(\mathrm{~d}, \mathrm{~J}=8.9 \mathrm{~Hz}$, $\left.\mathrm{H}_{1}\right), 8.16\left(\mathrm{~d}, \mathrm{~J}=8.4 \mathrm{~Hz}, \mathrm{H}_{\mathrm{e}}\right.$ ); UV-VIS ( $\mathrm{nm}$ in toluene $(\log \varepsilon)) 586(4.16)$ and $391(4.08)$.

7-(decyl-amino)-1, 3, 8, 10-tetramethyl-14nitrobenzo[1, 2, 3- $\left.k^{\prime} l^{\prime}: 4,5,6-k^{\prime} l^{\prime}\right]$ dixanthene (5). A mixture of $4(18 \mathrm{mg}, 0.0378 \mathrm{mmol}), 1$ iododecane $(30 \mathrm{mg}, 0.112 \mathrm{mmol}$ ), potassium iodide $(28.7 \mathrm{mg}, 0.173 \mathrm{mmol})$, and acetonitrile
$(17 \mathrm{ml})$ was heated at $80^{\circ} \mathrm{C}$ for $60 \mathrm{~h}$ under argon atmosphere. After evaporation of the solvent under reduced pressure, the residue was purified by column chromatography (chloroform/ silica gel and acetone/silica gel). Recrystallization from water afforded $5\left(7 \mathrm{mg}, 9.4 \times 10^{-3} \mathrm{mmol}\right.$, $25 \%$ ). Red purple powder; ${ }^{1} \mathrm{H}$ NMR $\left(\mathrm{CDCl}_{3} / \mathrm{TMS}, \delta \mathrm{ppm}\right) 3.73\left(\mathrm{t},{ }^{+} \mathrm{NHCH}_{2}{ }^{-}\right), 6.85$ $\left(\mathrm{d}, \mathrm{J}=4.25 \mathrm{~Hz}, \mathrm{H}_{\mathrm{f}}\right), 6.91\left(\mathrm{~s}, \mathrm{H}_{\mathrm{b}}\right), 7.09\left(\mathrm{~s}, \mathrm{H}_{\mathrm{i}}\right)$, $7.10\left(\mathrm{~s}, \mathrm{H}_{\mathrm{d}}\right), 7.44\left(\mathrm{~d}, \mathrm{~d}=9.24 \mathrm{~Hz}, \mathrm{H}_{\mathrm{f}}\right), 8.00(\mathrm{~s}$, $\left.\mathrm{H}_{\mathrm{k}}\right), 8.14\left(\mathrm{~d}, \mathrm{~J}=4.88 \mathrm{~Hz}, \mathrm{H}_{1}\right)$, and $8.17(\mathrm{~d}, \mathrm{~J}=$ $4.99 \mathrm{~Hz}, \mathrm{H}_{\mathrm{e}}$ ); UV-VIS ( $\mathrm{nm}$ in toluene) 570,540 , and 475.

\section{Acknowledgement}

We gratefully thank Mr. Y. Kogo, Nippon Kayaku Co., Ltd., for his useful advice in molecular orbital calculations.

\section{References}

1) S. Tokita, Kikan Kagaku Sosetsu, 28, 135 (1996).

2) S. Tokita, T. Watanabe, Y. Fujita, H. Iijima, and S. Terazono, Mol. Cryst. Liq. Cryst., 297, 269 (1997).

3) T. Watanabe, T. Tachikawa, N. Kitahara, and S. Tokita, Mol. Cryst. Liq. Cryst., 298, 1 (1997); Y. Kobayashi, S. Mochizuki, H. Yoshida, K. Nakatsu, T. Arai, T. Ishii, and S. Tokita, Proc. 2nd International Symp. on Chem. of Functional Dyes, Kobe, p. 425 (1992).

4) T. Watanabe, G. Yamakawa, S. Tokita, and H. Nakahara, J. Photopolym. Sci. Technol., 10(2), 255 (1997).

5) M. J. S. Dewar, E. G. Zoebisch, E. F. Healy and J. P. Stewart, J. Am. Chem. Soc., 107, 3902 (1985).

6) J. E. Ridley and M. C. Zerner, Theor. Chim Acta., 32, 111 (1973); A. D. Bacov and M. C. Zerner, Theor. Chim Acta., 53, 21 (1979); M. C. Zerner, G. H. Loew, R. F. Kirchner and U. T. Mueller-Westernhoff, J. Am. Chem. Soc., 102, 589 (1980); The authors express our hearty thanks to Professor M. C. Zerner for providing the ZINDO program.

7) S. Tokita, "Color Chemistry", Maruzen Co., Tokyo, p.115 (1982).

8) G. D. Purvis III, 3rd International Symp. on 
Chem. of Functional Dyes, Santa Cruz, PL-3 p.24 (1995); S. Tokita, T. Suzuki, T. Shimokoshi, Y. Kogo and K. Kafuku, J. Photopolym. Sci. Technol., 4, 41 (1991); S. Tokita, T. Suzuki and M. Nikaido, J. Photopolym. Sci. Technol., 5, 533 (1992).
9) S. Tokita, H. Naito, and H. Watanabe, Proc. 2nd. International Symp. on Chem. of Functional Dyes, Kobe, 428 (1992).

10) R. Schmidt, W. Drews and H. D. Brauer, $J$. Photochem., 18, 365 (1982). 